\title{
The Level of an Intracellular Antioxidant during Development Determines the Adult Phenotype in a Bird Species: A Potential Organizer Role for Glutathione
}

\author{
Ana Angela Romero-Haro ${ }^{1, \star}$ and Carlos Alonso-Alvarez ${ }^{1,2}$ \\ 1. Instituto de Investigación en Recursos Cinegéticos, Consejo Superior de Investigaciones Científicas, Universidad de Castilla-La \\ Mancha, Junta de Comunidades de Castilla-La Mancha, Ronda de Toledo s/n, 13071 Ciudad Real, Spain; 2. Museo Nacional de \\ Ciencias Naturales-Consejo Superior de Investigaciones Científicas, Department Ecología Evolutiva, Calle de José Gutiérrez Abascal 2, \\ 28006 Madrid, Spain
}

Submitted June 25, 2014; Accepted October 17, 2014; Electronically published January 21, 2015

Online enhancement: appendix. Dryad data: http://dx.doi.org/10.5061/dryad.1rd58.

\begin{abstract}
AвSTRACт: Life-history traits are often involved in trade-offs whose outcome would depend on the availability of resources but also on the state of specific molecular signals. Early conditions can influence trade-offs and program the phenotype throughout the lifetime, with oxidative stress likely involved in many taxa. Here we address the potential regulatory role of a single intracellular antioxidant in lifehistory trade-offs. Blood glutathione levels were reduced in a large sample of birds (zebra finch Taeniopygia guttata) during development using the synthesis inhibitor buthionine sulfoximine (BSO). Results revealed several modifications in the adult phenotype. BSO-treated nestlings showed lower glutathione and plasma antioxidant levels. In adulthood, BSO birds endured greater oxidative damage in erythrocytes but stronger expression of a sexual signal. Moreover, adult BSO females also showed weaker resistance to oxidative stress but were heavier and showed better body condition. Results suggest that low glutathione values during growth favor the investment in traits that should improve fitness returns, probably in the form of early reproduction. Higher oxidative stress in adulthood may be endured if this cost is paid later in life. Either the presence of specific signaling mechanisms or the indirect effect of increased oxidative stress can explain our findings.
\end{abstract}

Keywords: antioxidants, carotenoids, early development, hormesis, oxidative stress, zebra finches.

\section{Introduction}

Life-history traits are quantitative, demographic characteristics of individuals that are directly associated with the two main components of fitness: survival and reproduction. Growth pattern, age and size at maturity, reproductive investments, and longevity are all principal life-history traits (Braendle et al. 2011). The values of these traits are

\footnotetext{
* Corresponding author; e-mail: ana.romero@uclm.es.
}

Am. Nat. 2015. Vol. 185, pp. 390-405. (C) 2015 by The University of Chicago. 0003-0147/2015/18503-55578\$15.00. All rights reserved.

DOI: $10.1086 / 679613$ limited by factors internal to the organism, which are often described in the form of trade-offs. A trade-off takes place when an increased investment in one component of fitness leads to a decrease in the investment in another (e.g., early reproduction vs. longevity; Roff 2011; Stearns 2011).

The outcome of life-history trade-offs can be based on the limited availability of certain resources (e.g., time, energy, and micronutrients) that must be simultaneously allocated to different traits (i.e., the "Y" model; DeJong and van Noordwijk 1992; Zera and Harshman 2001). In the past decade, it has been proposed that the trade-off outcome may, alternatively or additionally, depend on the state of molecular intermediaries (signals), mostly hormones, such as insulin and insulin-like growth factors (Leroi 2001; Barnes and Partridge 2003; Lessells 2008). This challenges evolutionary theory, because molecular signals may sometimes act independently of resources, being able to simultaneously promote reproduction and survival (Leroi 2001; Barnes and Partridge 2003; Gerish and Antebi 2011).

Resource-based or signaling-based trade-offs would be critically influenced by the environment, which determines the resources and also triggers the signals (Lessells 2008; Alonso-Alvarez and Velando 2012). The environment can generate different phenotypes from a single genotype (i.e., phenotypic plasticity; West-Eberhard 2003). We also know that the earlier the environment impacts genotype, the stronger and longer lasting the effects are on adult phenotypes (Metcalfe and Monaghan 2001; Rinaudo and Wang 2012). It has been demonstrated that early conditions can program the phenotype for the duration of the lifetime. Among evolutionary and ecological studies, the case of offspring sex determination mediated by maternal sexual steroids can be highlighted, with hormones probably acting as signals of environmental conditions (e.g., 
Godwin et al. 2003; Pike and Petrie 2003). However, as in many cases in biology, the phenomenon has mostly been examined in the context of biomedicine, where terms such as "metabolic programming," "metabolic imprinting," and "metabolic syndrome" have been coined (e.g., Levin 2006; Kiani and Nielsen 2011; Rinaudo and Wang 2012). The study of the proximate mechanisms involved in this phenotypic programming has contributed to explaining modern diseases in humans (e.g., obesity, cardiovascular disease, and diabetes; McMillen and Robinson 2005; Rinaudo and Wang 2012). The availability of nutritional resources (lipids, proteins, and some specific amino acids) during early development has been the focus of most studies (mostly in mammalian species; e.g., McArdle et al. 2006; López-Torres and Barja 2008; Rinaudo and Wang 2012). A typical example is that of fetuses exposed to energy limitations during development, which leads to adult phenotypes adapted to an environment with scarce resources (the "thrifty phenotype" hypothesis; Hales and Barker 1992).

Other mechanisms, such as physiological stress (glucocorticoid-mediated stress; e.g., McMillen and Robinson 2005) and exposure to xenobiotics (e.g., Gore 2008) during early development, have also been addressed. Nonetheless, many authors (reviews in Luo et al. 2006; Nuyt and Alexander 2009; Tarry-Adkins et al. 2009; Dennery 2010; Hernandez-García et al 2010; Warner and Ozanne 2010; Thompson and Al-Hasan 2012) have noted that most of the cited mechanisms involve oxidative stress, which is the imbalance between the production of reactive species by cell metabolism or immune responses and the state and availability of antioxidant defenses (Halliwell and Gutteridge 2007). Oxidative stress was initially proposed as one of the main proximate causes of aging (e.g., Kirkwood and Austad 2000). Studies in rodents have shown that restriction in the availability of certain energy sources in the diet (i.e., proteins) during development reduces oxidative stress and, ultimately, increases life span (e.g., Tarry-Adkins et al. 2007; Chen et al. 2009 and references therein). Additionally, oxidative stress influences redox signals, governing important physiological pathways and modifying gene expression (Jones 2006; Ghezzi and Di Simplicio 2009). A key molecule in this framework is glutathione.

Glutathione is a tripeptide thiol that is often considered the most abundant and important intracellular antioxidant (Wu et al. 2004; Isaksson et al. 2011). Glutathione synthesis is influenced by environmental variability in different taxa. Accordingly, environmental temperature (houseflies: Rojas and Leopold 1996; fish: Leggatt et al. 2007; birds: Del Vesco et al. 2014; rats: DeQuiroga et al. 1991) and exposure to different pollutants (e.g., in birds: Galván and AlonsoAlvarez 2009; Wlostowski et al. 2010) significantly affect glutathione levels. Moreover, poor nutrition also depletes glutathione levels in pigs (Jahoor et al. 1995), laboratory rodents (e.g., Feoli et al. 2006; Fetoui et al. 2007; Partadiredja et al. 2009), and humans (e.g., Reid et al. 2000). We must here note that glutathione is synthesized by the cell from cysteine and other amino acids, such as methionine (Wu et al. 2004; Isaksson et al. 2011; Lu 2013). This implies that glutathione synthesis depends on protein (amino acid) availability in the diet (Lu 2013). In developing chicken, cysteine (Chung et al. 1990; Enkvetchakul and Bottje 1995) and methionine (Nemeth et al. 2004; Swennen et al. 2011) supplementation in food increases glutathione levels. In wild conditions, Isaksson (2013) has also found that great tits (Parus major) feeding on deciduous forests carried lower circulating glutathione levels than did birds feeding on evergreen forests and suggests that it could be due to different availability of dietary amino acids between habitats. Cumulatively, these studies suggest that glutathione levels could potentially be used as a chemical cue signaling ecological changes.

Glutathione neutralizes hydrogen peroxide, producing oxidized glutathione (GSSG) that is subsequently recycled to reduced glutathione (GSH), with the process as a whole requiring a number of specific enzymes (e.g., gluthathione peroxidase and reductase; $\mathrm{Wu}$ et al. 2004). The GSH : GSSG ratio is thus tightly regulated, with an imbalance to low ratios indicating higher oxidative stress (Halliwell and Gutteridge 2007). Studies in the past several decades have revealed the importance of thiols in general, and glutathione in particular, in cell (redox) signaling (Ghezzi and Disimplicio 2009; Sohal and Orr 2012; Ghezzi 2013). Glutathione is even able to penetrate the cell nucleus, probably altering gene expression in animals (Markovic et al. 2010). All of this makes glutathione a potentially important signal involved in the outcome of life-history trade-offs (Isaksson et al. 2011). However, its role in this context has been barely studied.

Here, we studied the influence of glutathione levels in the expression of different life-history traits in a wellknown avian species, the zebra finch (Taeniopygia guttata). We used a specific inhibitor of glutathione synthesis, buthionine sulfoximine (BSO), a compound that selectively blocks the activity of the enzyme glutamate cysteine ligase (also $\gamma$-glutamylcysteine synthetase; Griffith 1982), the first enzyme in the glutathione biosynthesis pathway $(\mathrm{Wu}$ et al. 2004). The BSO action is restricted to glutathione depletion and its consequences (e.g., Griffith 1982; Mårtensson et al. 1991). After determining BSO doses by means of a pilot study and previous work (i.e., Galván and Alonso-Alvarez 2008), we decreased glutathione levels in a large sample of nestlings and then assessed the impact of BSO on growth pattern, survival, and adult phenotype, including body mass and size, a number of markers of oxidative stress in blood (antioxidant levels and oxidative 


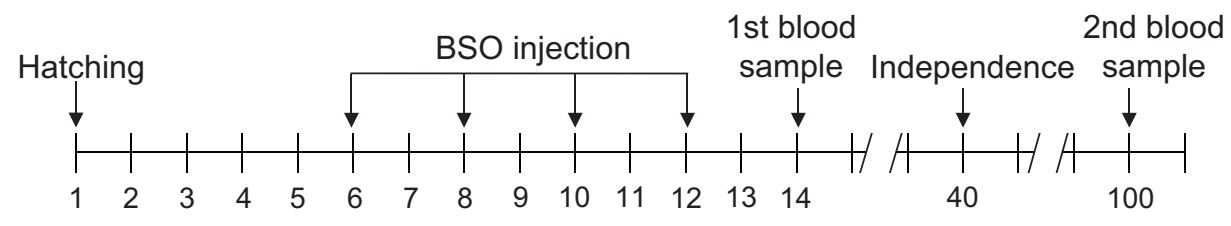

Figure 1: Chronogram of the experiment. $\mathrm{BSO}=$ buthionine sulfoximine.

damage indices), circulating levels of protein and fat metabolites (uric acid [UA] and triglycerides [TRG], respectively), and the expression of colored traits, including a sexual signal (i.e., bill color; Burley 1986; Simons et al. 2012). Early development is a life stage in which oxidative stress levels should be high due to the link between the high metabolic activities required for growth and reactive species generation (Metcalfe and Alonso-Alvarez 2010 and references therein). If glutathione depletion only leads to oxidative stress and damage (e.g., Horak et al. 2010), and given the role of perinatal oxidative stress in human diseases in adulthood (e.g., Nuyt and Alexander 2009; Warner and Ozanne 2010), we may predict that low glutathione levels during growth should constrain development and adult fitness-related traits. We may also, alternatively, predict that low glutathione levels experienced during growth could serve as a signal of a future adverse environment, promoting any phenotypic change favoring individual fitness.

\section{Material and Methods}

Eighty randomly formed zebra finch pairs were housed in breeding cages $(0.6 \mathrm{~m} \times 0.4 \mathrm{~m} \times 0.4 \mathrm{~m})$ with a nestbox $(11 \mathrm{~cm} \times 13 \mathrm{~cm} \times 13 \mathrm{~cm})$, receiving water and food (a commercial mix of seeds; KIKI, Callosa de Segura, Spain) ad lib.. Temperature (mean temperature, $22^{\circ} \pm 1^{\circ} \mathrm{C}$ ) and light-dark daily cycles $(16 \mathrm{~L}: 8 \mathrm{D})$ were controlled. The pairs bred over a 5-month period. Twelve pairs did not breed during the experiment, 22 pairs reproduced once, 22 pairs reproduced twice, 21 pairs reproduced three times, and three pairs produced four broods. Reproduction was monitored every 2 days.

The experimental schedule is shown in figure 1 . The treatment was applied to chicks when they reached a minimum body mass of $3 \mathrm{~g}$ (mean $\pm \mathrm{SE}, 4.82 \pm 0.03 \mathrm{~g}$ ). Half of the nestlings in a brood were randomly assigned to a treatment receiving DL-buthionine-S,R-sulfoximine (BSO; Sigma, ref. B2640) diluted in sterilized normal saline solution $(0.90 \% \mathrm{w} / \mathrm{v}$ of $\mathrm{NaCl})$, and the other half received sterilized saline only (controls). The BSO dose was calculated from a pilot experiment and based on a previous work involving great tit (Parus major) nestlings (Galvan and Alonso-Alvarez 2008). The pilot study used 10 breeding zebra finch pairs and 26 nestlings. Total glutathione (tGSH) in erythrocytes was determined in 14-day-old nestlings, and then a dose producing a moderate but significant decrease was chosen $(50 \mathrm{mg} / \mathrm{mL})$.

In the final experiment, a volume of $0.06 \mathrm{~mL}$ of the solution/saline was subcutaneously injected in the back every 2 days from 6 to 12 days old (i.e., four injections). BSO chicks received a total of $12 \mathrm{mg}$ BSO. We randomly allocated a treatment to the heaviest chick in a brood and then successively alternated the treatment category among its siblings (e.g., control, BSO, control, BSO). Twelve nestlings were excluded from the study because they erroneously received a mix of the two treatments. Sample sizes were thus 206 and 203 birds for BSO-treated and control nestlings, respectively. A blood sample was collected for each bird 8 days after the start of the injection period (fig. 1; mean age, 14 days). Blood was taken from the brachial vein by means of heparinized capillaries. Males and females were separately housed in different rooms $(2.80 \mathrm{~m}$ $\times 3 \mathrm{~m} \times 2.50 \mathrm{~m}$ ) when they reached approximately 40 days of age (mean age \pm SE, $39 \pm 0.12$ days), an age at which all of the birds were independent (Zann 1996; Alonso-Alvarez et al. 2006). The rooms had controlled temperatures (mean temperature $\pm \mathrm{SE}, 22^{\circ} \pm 1^{\circ} \mathrm{C}$ ), food and water were provided ad lib., and the rooms were not acoustically isolated. A second blood sample was collected from the jugular vein in adulthood (mean age \pm SE, 97.8 \pm 0.84 days). For simplicity, we will use 40 days and 100 days to show the mean age at the independence and adulthood sampling events, respectively. The blood samples were immediately stored at $4^{\circ} \mathrm{C}$ in Eppendorf tubes and centrifuged $(5,000 \mathrm{~g}, 5 \mathrm{~min})$ within $4 \mathrm{~h}$. An aliquot of blood was used to calculate the hematocrit. The plasma was removed and the buffy coat discarded by pipetting. Plasma and erythrocyte (red blood cell [RBC]) fractions were separately stored at $-80^{\circ} \mathrm{C}$.

In adulthood (at 100 days; i.e., when the second blood sample was taken), a digital picture of the upper surface of the upper mandible was obtained by placing the bird in a prone position. Another picture of the breast was obtained for adults by placing the animal in a supine position (see also appendix, available online). Finally, the 
tarsus length and the body mass of each individual were measured on the day of first injection, first blood extraction, independence, and adulthood.

\section{Molecular Sexing}

Nestlings that were not sexed by their sexually dimorphic traits were molecularly sexed from a subsample of the RBC fraction. DNA from sex chromosomes was amplified with polymerase chain reaction using the primers $002 \mathrm{R}, 0057 \mathrm{~F}$ (Round et al. 2007). We were unable to sex 10 chicks that died before the first blood sampling and whose body samples were contaminated.

\section{Glutathione Levels in RBCs}

Glutathione was quantified following the Griffith (1980) method with modifications (appendix). To attain the glutathione oxidation rate, GSH was calculated by subtracting GSSG from tGSH levels. Subsequently, the ratio GSH : GSSG was obtained (Owen and Butterfield 2010).

\section{Plasma Antioxidants}

A technique often called total antioxidant status was assessed to estimate the availability of nonenzymatic antioxidants. Because the idea that this measure assesses all the antioxidants is questionable, the term "total" was avoided, and hence, we will use only a generic "plasma antioxidants" (PLAOX). The procedure is based on Miller et al. (1993), modified by Cohen et al. (2007; also appendix).

Total carotenoids in plasma were quantified because of their antioxidant properties and the fact that they result in the red coloration of zebra finch bills (McGraw and Toomey 2010). Values were determined by spectrophotometry (446 nm), using lutein as the standard (appendix).

\section{Erythrocyte Resistance to Oxidative Stress in Adults}

The resistance to oxidative stress in adult birds was assessed by measuring the time needed to hemolyze $50 \%$ of the RBCs exposed to a controlled free radical attack (e.g., Alonso-Alvarez et al. 2006). The principle of this in vitro test is to submit whole blood to thermo-controlled free radical aggression by adding 2,2-azobis-(aminodinopropane) hydrochloride, measuring the decrease in optical density of the solution (appendix).

\section{Oxidative Damage in Lipids}

The protocol described in Agarwal and Chase (2002) with modifications by Nussey et al. (2009) was followed to as- sess the amount of a product of lipid peroxidation named malondialdehyde (MDA; Halliwell and Gutteridge 2007). The test was performed on plasma and erythrocyte suspensions separately (appendix).

\section{Plasma TRG and UA}

The glycerol phosphate oxidase/peroxidase method and the uricase/peroxidase method were used for measuring TRG and UA levels, respectively, by means of commercial kits (Biosystems, Barcelona; appendix).

\section{Color Measurements}

The area of the black bib was measured only in males, because females do not exhibit a conspicuous bib (Zann 1996). Adobe Photoshop CS3 was used. Two measures of the bib were taken: the homogeneous black zone only (selected manually) and the total area including the horizontal black stripes (using the magic wand tool in Adobe with a fixed tolerance). The area of a standard chip (Kodak) was also measured and added as a covariate in the models (see "Statistical Analyses").

The color intensity of the bill was determined in adults by recording mean red, green, and blue values (RGB system; Alonso-Alvarez et al. 2008) using Adobe Photoshop CS3. We have previously observed that redness measurements using this technique highly correlate $(r=0.86)$ with similar measurements taken with a spectrophotometer (Avantes DH-2000 spectrometer) including the ultraviolet spectrum (300-400 nm; Alonso-Alvarez and Galván 2011; appendix). Hue was determined after conversion of RGB values by using the Foley and Van Dam (1984) algorithm. High hue values denote low red intensity. To control for subtle variations in illumination between pictures, the hue of a red chip placed close to the bird (appendix) was added as a covariate in models testing hue as the dependent variable (see "Statistical Analyses") and always retained (all $P<.05$ ). All of the image measurements were performed by a technician blind to bird identity.

\section{Statistical Analyses}

We used SAS, version 9.3 (Cary, NC), for statistical analyses. Generalized mixed models (MIXED procedure; Littell 2006) were used to control for shared genes and environment. Data were thus cross-classified by introducing the identity of the brood nested into the identity of the cage (i.e., a single cage with the same parents could produce several broods; see above) as a random factor $(P<.001$ to $P=.428$ ). The identity of the session was also added as an additional random factor in models testing physiological variables $(P<.001$ to $P=.448)$. The treatment 
(control vs. BSO), the sex, and their interaction were always tested. A number of covariates were added to control for potential confounding effects: number of reproduction for a given pair (brood number), hatching date, squared hatching date (for quadratic relationships), hatching order, brood size, age and mass at the first injection, age at independence, and age at the time of the last sampling event. The age at the first injection and the age at adulthood were also considered for models testing physiological variables. In addition, because we previously detected a negative correlation between tGSH values and plasma carotenoid levels in nestlings but not adult zebra finches (Romero-Haro and Alonso-Alvarez 2014a), here we tested a potential influence of the treatment on the correlation of these variables. In this order, alternative models on tGSH variability (dependent variable) included carotenoid level as a covariate, testing its interactions with treatment and sex. In this case, the intercept of the model was also included as a random term following Schielzeth and Forstmeier (2009). Plasma TRG and UA levels were also added as covariates to control for the potential confounding influences (positive links) of recent food intake on plasma MDA and PLAOX models, respectively (see studies by Costantini [2011] and Romero-Haro and Alonso-Alvarez $[2014 a])$. Physiological variables were recalculated as residuals from models controlling for random effects when used as covariates (i.e., UA, TRG, and carotenoids). To detect initial bias among fledglings, different mixed models were also performed on initial body mass, initial tarsus length, initial size-corrected body mass (body condition; i.e., adding tarsus length to a model with body mass as the dependent variable), and age at the time of the first injection (i.e., the start of the experiment).

The procedure GLIMMIX in SAS was used for those dependent variables that were not normally distributed (i.e., mortality) or nonnormalizable after transformation (i.e., age at first injection). In these two cases, the type of distribution and link function were specified (mortality: binomial and logistic; age at first injection: multinomial and cumulative logistic; Gibbs 2008).

To explore the change in body mass and size, repeatedmeasurement mixed models (also PROC MIXED in SAS) were used. The mean age (6-, 14-, 40-, and 100-day-old sampling bouts) was added as a four-level fixed factor in every model, testing interactions with treatment and sex. In these models, in addition to the identity of the brood nested into the identity of the cage (random factors; RANDOM statement), the age was included as a repeatedmeasure factor and the identity of the individual as a subject term (REPEATED statement). The tarsus length was added as a covariate to test changes in body condition (size-corrected body mass). Repeated-measurement mixed models were not used for testing physiological variables (above) because the low masses of 4-day-old nestlings prevented the collection of sufficient blood volume for obtaining pretreatment values without risking bird survival.

Different procedures for selecting the best-fitted model were used (forward and backward stepwise procedures and the Akaike information criterion), and they all showed similar results. For simplicity, only the results of backward procedures were shown, removing all nonsignificant terms at $P<.10$. Moreover, the models remained significant when all the covariates used for controlling potential confounding effects (see above) were removed (i.e., even when significant). The reported means and standard errors (SEs) are always least square means and SEs obtained from the models. Degrees of freedom were calculated by the BETWITHIN option in SAS (Littell 2006). Least significant difference post hoc tests were used for pairwise comparisons. Blood volume was not sufficient to perform all the analytical techniques in every individual, which affected degrees of freedom. The reported tests and $P$ values for factors and covariates are those from the best-fitted models or those obtained at the time of removal following the selection model procedure. The effect of sex independent of treatment (without interaction) is described in the text only when significant $(P<.05)$. Variables GSH : GSSG, adult PLAOX, and hue were log transformed to reach normality. Effect sizes for significant comparisons are reported as Cohen's $d$ (Cohen 1992). Data used in this study are deposited in the Dryad Digital Repository (http://dx .doi.org/10.5061/dryad.1rd58; Romero-Haro and AlonsoAlvarez 2014b).

\section{Results}

Initial Values

The age at the start of the treatment did not differ between control and BSO-treated chicks (treatment: $F_{1,268}=0.68$, $P=.410$; treatment $\times$ sex interaction: $F_{1,256}=0.25, P=$ .615). No initial significant differences between treatments in body mass (treatment: $F_{1,407}=1.25, P=.264$; treatment $\times$ sex: $F_{1,395}=0.06, P=.809$ ), tarsus length (treatment: $F_{1,403}=1.22, P=.269$; treatment $\times$ sex: $F_{1,391}=$ 2.46, $P=.118$ ), or body condition (treatment: $F_{1,402}=$ $0.50, P=.479$; treatment $\times$ sex: $\left.F_{1,390}=0.84, P=.360\right)$ were found.

\section{The Manipulated Variable: Glutathione}

BSO nestlings showed lower tGSH concentrations than control nestlings (table 1; fig. 2). The difference was $13 \%$ (Cohen's $d=0.78$ ). Individual values were well overlapped between treatments (see "Oxidative Stress Markers"). Adults showed even lower levels (fig. 2) but did not 
Table 1: Best-fitted mixed models testing the impact of the manipulation of glutathione levels during development on different physiological variables

\begin{tabular}{|c|c|c|c|c|c|}
\hline Dependent variable, terms in the model & Slope & SE & $F$ & df & $P$ \\
\hline \multicolumn{6}{|l|}{ Nestling RBC tGSH: } \\
\hline Treatment & $\cdots$ & $\ldots$ & 56.83 & 1,374 & $<.001$ \\
\hline Initial age & -.116 & .031 & 14.09 & 1,374 & $<.001$ \\
\hline \multicolumn{6}{|l|}{ Nestling PLAOX: } \\
\hline Sex & $\ldots$ & $\cdots$ & 3.68 & 1,370 & .056 \\
\hline Treatment & $\ldots$ & $\ldots$ & 5.78 & 1,370 & .017 \\
\hline Initial age & .036 & .006 & 35.86 & 1,370 & $<.001$ \\
\hline \multicolumn{6}{|l|}{ Adult RBC MDA: } \\
\hline Sex & $\ldots$ & $\ldots$ & 5.77 & 1,266 & .0169 \\
\hline Treatment & $\ldots$ & $\ldots$ & 6.69 & 1,266 & .0102 \\
\hline Hatching date & .1609 & .07002 & 5.28 & 1,266 & .022 \\
\hline \multicolumn{6}{|l|}{ Adult RBC resistance to oxidative stress: } \\
\hline Sex & $\ldots$ & $\ldots$ & .05 & 1,270 & .829 \\
\hline Treatment & $\ldots$ & $\ldots$ & .64 & 1,270 & .423 \\
\hline Sex $\times$ treatment & $\ldots$ & $\ldots$ & 4.97 & 1,270 & .027 \\
\hline Initial age & .9483 & .4188 & 5.13 & 1,270 & .024 \\
\hline
\end{tabular}

Note: Only variables with $P \leq .10$ remain in the table. SE: standard error; $\mathrm{df}=$ degrees of freedom; $\mathrm{RBC}=$ red blood cell; $\mathrm{tGSH}=$ total glutathione; PLAOX = hydrosoluble plasma antioxidants; MDA = malondialdehyde.

show a difference between groups (treatment: $F_{1,288}=$ $1.12, P=.290$; treatment $\times$ sex: $\left.F_{1,287}=0.26, P=.613\right)$. Adult females showed higher tGSH levels than adult males $\left(F_{1,289}=4.56, P=.034\right.$; mean $\pm \mathrm{SE}, 3.82 \pm 0.049 \mu \mathrm{mol} /$ $\mathrm{g}$ in males and $3.95 \pm 0.05 \mu \mathrm{mol} / \mathrm{g}$ in females; $d=0.25$ ). With regard to the GSH : GSSG ratio, the treatment and its interaction with sex were not significant among nestlings $\left(F_{1,369}=0.12, P=.728\right.$, and $F_{1,368}=0.51, P=.477$, respectively) or adults $\left(F_{1,279}=0.95, P=.330\right.$ and $F_{1,278}=2.47, P=.117$, respectively).

\section{Mortality}

Mortality at the age of the first blood-sampling event, at the end of the injection period (14 days), did not significantly differ between treatments $\left(F_{1,280}=1.39, P=.239\right.$; control group: $n=10$ [4.75\%]; BSO group: $n=16$ [7.77\%]). Because a few nestlings that died before the first blood-sampling event could not be sexed (see "Material and Methods"), the treatment $\times$ sex interaction was tested in another model that included sexed birds only. That model did not show any significant trend (treatment: $F_{1,269}=0.05, P=.830$; treatment $\times$ sex: $F_{1,268}=0.01$, $P=.918)$. Similarly, the accumulated mortality at the independence stage $(11.5 \%)$ did not show significant differences (treatment: $F_{1,269}=0.02, P=.880$; treatment $\times$ sex: $\left.F_{1,268}=0.37, P=.542\right)$. The same variable in adulthood blood sampling (22.9\%) showed similar results (treatment: $F_{1,269}=0.01, P=.973$; treatment $\times$ sex: $\left.F_{1,268}=0.01, P=.966\right)$.

\section{Body Mass and Body Size Changes}

In repeated mixed models, a number of differences among treatments in morphological variables were detected (table 2). First, the body mass showed a significant three-order interaction between age of sampling, sex, and treatment (fig. 3A). The treatment did not differ in males at any age (always $P>.27$ ). In females, in contrast, the body mass did not differ between treatments at 14 days old $(P=$ .480 ), but differences arose with time (40 days old: $P=$

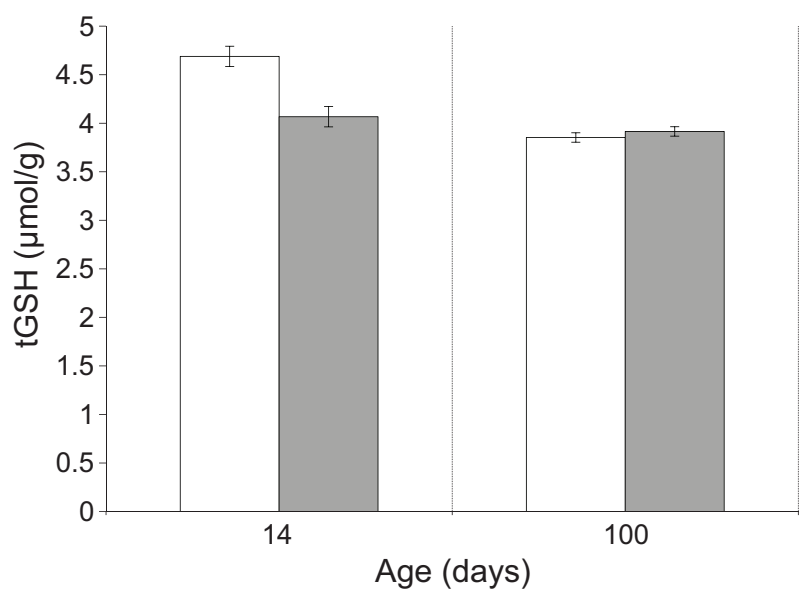

Figure 2: Total glutathione (tGSH) erythrocyte levels at 14 and 100 days of age. White and gray bars show control and buthionine sulfoximine-treated birds, respectively. Least square means \pm SE from mixed models. 
Table 2: Mixed models testing the impact of the manipulation of glutathion levels during development on morphological variables

\begin{tabular}{|c|c|c|c|c|c|}
\hline Dependent variable, terms in the model & Slope & SE & $F$ & df & $P$ \\
\hline \multicolumn{6}{|l|}{ Body mass: } \\
\hline Age & $\cdots$ & $\cdots$ & $5,210.8$ & 3,1039 & $<.001$ \\
\hline Treatment & $\cdots$ & $\ldots$ & 1.78 & 1,392 & .183 \\
\hline Sex & $\ldots$ & $\ldots$ & .20 & 1,392 & .658 \\
\hline Treatment $\times$ sex & $\ldots$ & $\ldots$ & 2.78 & 1,392 & .096 \\
\hline Treatment $\times$ age & $\ldots$ & $\ldots$ & 1.33 & 3,1039 & .263 \\
\hline Sex $\times$ age & $\ldots$ & $\ldots$ & 3.52 & 3, 1039 & .015 \\
\hline Treatment $\times$ sex $\times$ age & $\ldots$ & $\cdots$ & 2.76 & 3,1039 & .039 \\
\hline Hatching date & .004 & .002 & 2.98 & 1,392 & .085 \\
\hline Hatching order & -.176 & .029 & 36.03 & 1,392 & $<.001$ \\
\hline Initial age & -.099 & .027 & 13.61 & 1,392 & $<.001$ \\
\hline \multicolumn{6}{|l|}{ Size-corrected body mass (body condition): } \\
\hline Age & $\ldots$ & $\ldots$ & $1,190.3$ & 3,1033 & $<.001$ \\
\hline Treatment & $\ldots$ & $\ldots$ & 1.30 & 1,392 & .256 \\
\hline Sex & $\ldots$ & $\ldots$ & .42 & 1,392 & .519 \\
\hline Treatment $\times$ sex & $\ldots$ & $\ldots$ & 19.04 & 1,392 & $<.001$ \\
\hline Treatment $\times$ age & $\ldots$ & $\ldots$ & .76 & 3,1033 & .517 \\
\hline Sex $\times$ age & $\ldots$ & $\ldots$ & 3.46 & 3,1033 & .016 \\
\hline Treatment $\times$ sex $\times$ age & $\ldots$ & $\ldots$ & 2.84 & 3,1033 & .037 \\
\hline Tarsus length & .888 & .026 & $1,207.3$ & 1,1033 & $<.001$ \\
\hline Brood number & .189 & .063 & 8.96 & 1,392 & .003 \\
\hline Hatching order & -.088 & .020 & 19.77 & 1,392 & $<.001$ \\
\hline Initial age & -.133 & .017 & 58.68 & 1,392 & $<.001$ \\
\hline
\end{tabular}

Note: Only variables with $P \leq .10$ remain in the table. Boldface type indicates the main significant interaction. $\mathrm{SE}=$ standard error; $\mathrm{df}=$ degrees of freedom.

$.019, d=0.36 ; 100$ days old: $P=.007, d=0.45)$, with BSO females being heavier than control females. When comparing data among ages (fig. $3 A$ ), the body mass of BSO males decreased from 40 to 100 days old $(P=.010$, $d=0.40)$, whereas it did not decrease in control males $(P=.115)$. No change at these ages was detected in females (control females: $P=.591$; BSO females: $P=.494$ ).

In the case of tarsus (fig. $3 B$ ), the treatment did not interact with age and sex (three-way interaction: $F_{3,1034}=0.84, P=.471$ ) or with age alone (treatment $\times$ age: $\left.F_{3,1042}=0.57, P=.635\right)$. In the case of size-corrected body mass (body condition), the treatment again showed a significant three-way interaction with age and sex (table 2; fig. 3C). In males, the differences between treatments were not significant at 14 and 40 days (both $P>.179$ ). However, the BSO males tended to show a poorer body condition than control males in adulthood $(P=.068)$. In females, differences were not detected at 14 days old $(P=$ $.275)$ but arose at 40 and 100 days $(P=.005, d=0.44$, and $P=.008, d=0.44$, respectively; fig. $3 C$ ), with $\mathrm{BSO}$ females showing better condition than control females. When comparing ages, the body condition of BSO males decreased from 40 to 100 days $(P=.028, d=0.34)$, but control males and females did not show a significant change $(P>.117)$.

\section{Oxidative Stress Markers}

BSO nestlings showed lower PLAOX levels than control nestlings (table 1; fig. $4 A ; d=0.24$ ). This did not change when PLAOX was corrected by UA variability $\left(F_{1,360}=\right.$ $5.22, P=.023, d=0.24)$. In adults, no significant difference was found in uncorrected (treatment: $F_{1,283}=$ 2.46, $P=.118$; treatment $\times$ sex: $\left.F_{1,282}=0.01, P=.968\right)$ or UA-corrected (treatment: $F_{1,277}=0.69, P=.406$; treatment $\times$ sex: $\left.F_{1,276}=0.06, P=.804\right)$ PLAOX levels.

Carotenoid values did not differ between treatments in nestlings (treatment: $F_{1,367}=1.67, P=.197$; treatment $\times$ sex: $F_{1,364}=0.29, P=.589$ ) or adults (treatment: $F_{1,283}=0.11, P=.744$; treatment $\times$ sex: $F_{1,281}=0.20$, $P=.657)$. When testing the link between tGSH values in RBCs and carotenoid plasma levels among nestlings (see fig. 5 for raw data), the slope differed between treatments (treatment $\times$ carotenoid level: $F_{1,365}=4.80, P=.029$ ), with control birds showing a significant negative link $\left(F_{1,182}=9.30, P=.003\right.$; slope \pm SE: $-0.035 \pm 0.012 \mu \mathrm{g} /$ $\mathrm{mL})$, whereas BSO birds did not $\left(F_{1,181}=0.54, P=.462\right.$; slope $\pm \mathrm{SE},-0.010 \pm 0.013 \mu \mathrm{g} / \mathrm{mL}$ ). The tGSH and carotenoid levels did not correlate in adults (carotenoid covariate: $F_{1,290}=0.35, P=.554$; treatment $\times$ carotenoid levels: $\left.F_{1,289}=0.14, P=.711\right)$. 


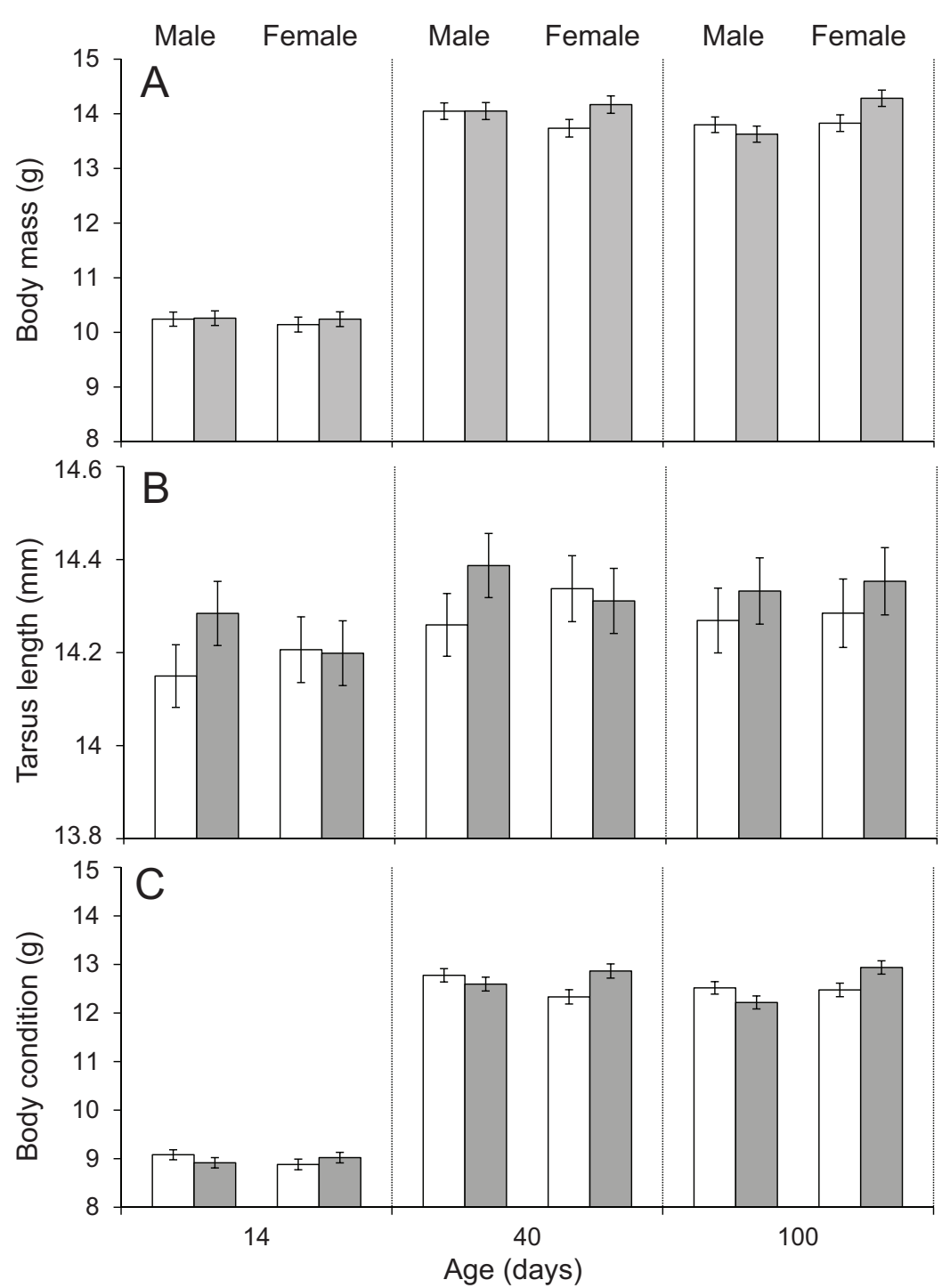

Figure 3: Body mass $(A)$, tarsus length $(B)$, and body condition (size-corrected body mass; $C$ ) at 14, 40, and 100 days of age. White and gray bars represent control and buthionine sulfoximine-treated birds, respectively. Least squared means \pm SE from mixed models.

BSO nestlings showed higher mean RBC MDA levels than controls (fig. $4 B$ ), although the effect was not significant $\left(F_{1,343}=2.16, P=.142\right)$. However, the effect was significant in adults (table 1; fig. $4 B ; d=0.32$ ).

The treatment did not influence plasma MDA. No difference between treatments was found among nestlings (treatment: $F_{1,371}=0.10, P=.747$; treatment $\times$ sex: $\left.F_{1,370}=0.37, P=.545\right)$. When plasma MDA levels were corrected by TRG values (covariate always $P<.001$; Romero-Haro and Alonso-Alvarez 2014b), the results did not change (treatment: $F_{1,356}=0.51, P=.475$; treatment $\times$ sex: $\left.F_{1,355}=0.72, P=.396\right)$. Similarly, plasma MDA levels in adulthood did not differ between treatments (treat- ment: $F_{1,296}=0.35, P=.555$; treatment $\times$ sex: $F_{1,293}=$ $0.01, P=.997)$. Nevertheless, adult males showed lower plasma MDA levels than females $\left(F_{1,302}=3.87, P=.050\right.$; males: $5.56 \pm 0.40 \mu \mathrm{M}$; females: $6.10 \pm 0.41 \mu \mathrm{M} ; d=$ $0.23)$. When the plasma MDA levels were corrected by TRG (always $P<.001$ ), the effect became stronger (sex: $F_{1,293}=8.13, P=.005$; males: $5.47 \pm 0.41 \mu \mathrm{M}$; females: $6.23 \pm 0.41 \mu \mathrm{M}$; treatment: $F_{1,286}=0.13, P=.716$; treatment $\times$ sex: $F_{1,284}=0.08, P=.778 ; d=0.33$ ).

Finally, a significant treatment $x$ sex interaction was found in erythrocyte resistance to oxidative stress (table 1; fig. 4C). Erythrocytes of adult BSO females were less resistant than those of adult control females $(P=.038$; 

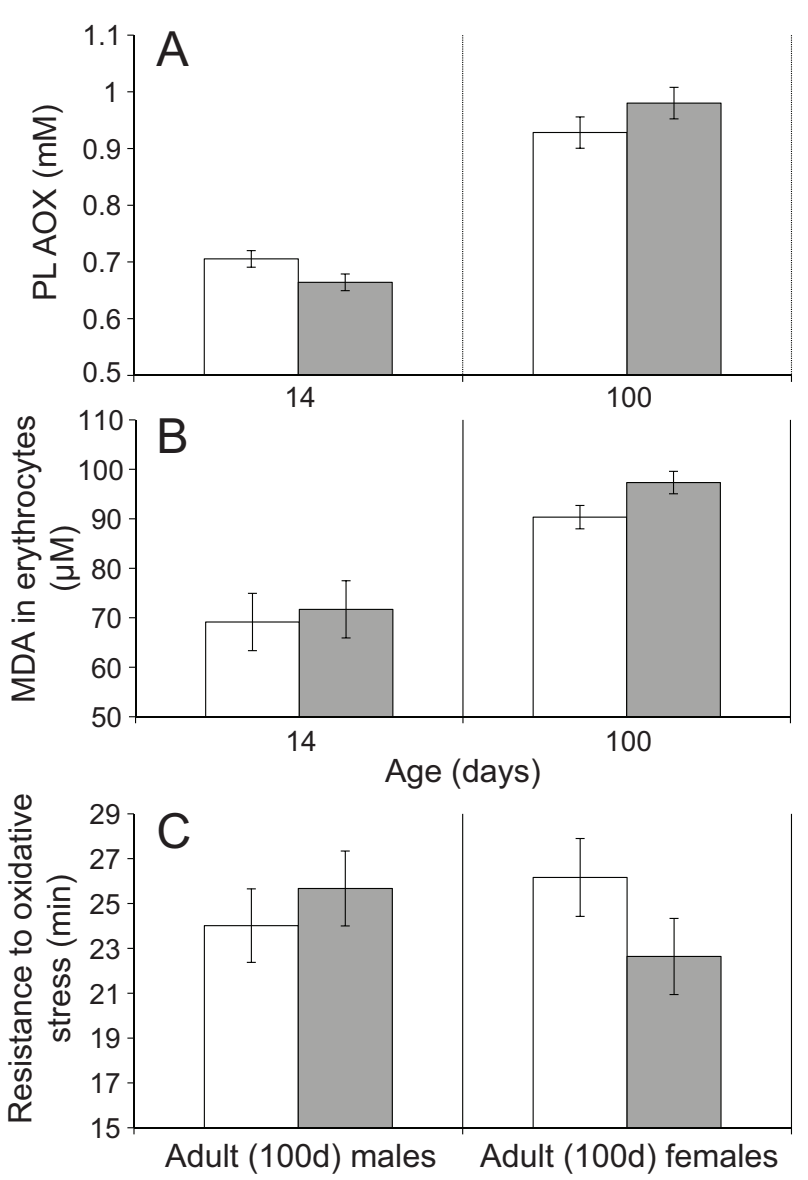

Figure 4: Effects on oxidative stress markers: plasma antioxidant (PLAOX) capacity $(A)$, oxidative damage in erythrocyte lipids (i.e., malondialdehydes; MDA) both at different ages $(B)$, and erythrocyte resistance against oxidative stress-mediated hemolysis (time to hemolyze $50 \%$ of cells; $C$ ). White and gray bars represent control and buthionine sulfoximine-treated birds, respectively. Least squared means \pm SE from mixed models. PLAOX levels in adults were not $\log$ transformed to agree with nestling values.

Cohen's $d=0.37)$. Erythrocytes of adult males did not differ $(P=.302$; fig. $4 C)$. The result was independent from hematocrit, because it was not significant when tested as a covariate $\left(F_{1,258}=0.81, P=.369\right)$.

\section{Expression of Ornaments}

The total area of the bib of adult males did not differ between treatments $\left(F_{1,152}=0.69, P=.407\right)$, nor did the main black area alone (i.e., excluding the stripes; $\left.F_{1,152}=0.71, P=.402\right)$. In the bill, the interaction between treatment and sex was not significant $\left(F_{1,279}=\right.$ $0.16, P=.685)$. However, BSO birds developed redder bills (lower hue) than controls $\left(F_{1,280}=4.51, P=.035\right.$; Cohen's $d=0.25$; fig. 6$)$, independently of $\operatorname{sex}\left(F_{1,280}=\right.$
68.05, $P<.001$; males: $0.98 \pm 0.01$, females: $1.15 \pm 0.01$ ). Other covariates in the model were the hatching order $\left(F_{1,280}=4.53, P=.034\right.$; slope: $\left.0.006 \pm 0.003\right)$, body mass at the start of the experiment $\left(F_{1,280}=3.19, P=.075\right.$; slope: $-0.009 \pm 0.005)$, and age at sampling $\left(F_{1,280}=\right.$ $32.43, P<.001$; slope: $-0.002 \pm 0.001)$. The difference between treatments remained when covariates were removed $\left(F_{1,283}=4.21, P=.041\right)$.

\section{Discussion}

Our results illustrate that a change in the intracellular concentration of a single antioxidant during development can induce deep modifications in the expression of the adult phenotype. Nestlings whose tGSH synthesis was partially inhibited during a short time period showed lower RBC tGSH and PLAOX levels compared with controls. In adulthood, compared with controls, BSO birds showed greater oxidative damage in erythrocytes, but they also showed greater expression of a sexual signal (the red color of the bill). Adult BSO females also showed weaker resistance to oxidative stress-mediated hemolysis but were heavier and showed better body condition (size-corrected body mass) than control females. Results mostly support the second scenario predicted in our introduction; that is, birds favored the investment in traits that should in some way improve fitness.

One important point here is whether a transient decrease in glutathione levels during development re-creates a natural (ecologically) relevant situation. Several lines of evidence suggest that it does. First, the dependence of glutathione levels on food availability during development has been broadly demonstrated, at least in mammals (e.g., Jahoor et al. 1995; Reid et al. 2000; Feoli et al. 2006; Fetoui et al. 2007; Partadiredja et al. 2009). Second, in developing poultry, supplementation of dietary amino acid precursors of glutathione increases the levels of this antioxidant (Enkvetchakul and Bottje 1995; Nemeth et al. 2004; Swennen et al. 2011). Third, in wild birds (great tits), individuals foraging in different habitats circulate different levels of glutathione, which was attributed to differences in the availability of precursors in the diet (Isaksson 2013). Finally, although our study was performed in captivity conditions, we observed substantial variation in tGSH levels in control birds, the treatment simply shifting the proportion of birds falling in the lower half of that apparently natural range (fig. 5).

To our knowledge, only four avian studies have used BSO and effectively decreased tGSH values (Galvani et al. 1998; Marchionatti et al. 2001; Galván and Alonso-Alvarez 2008; Horak et al. 2010). Among them, the subject of the study was related to the present work in only two cases. In Galván and Alonso-Alvarez (2008), wild nestling great 


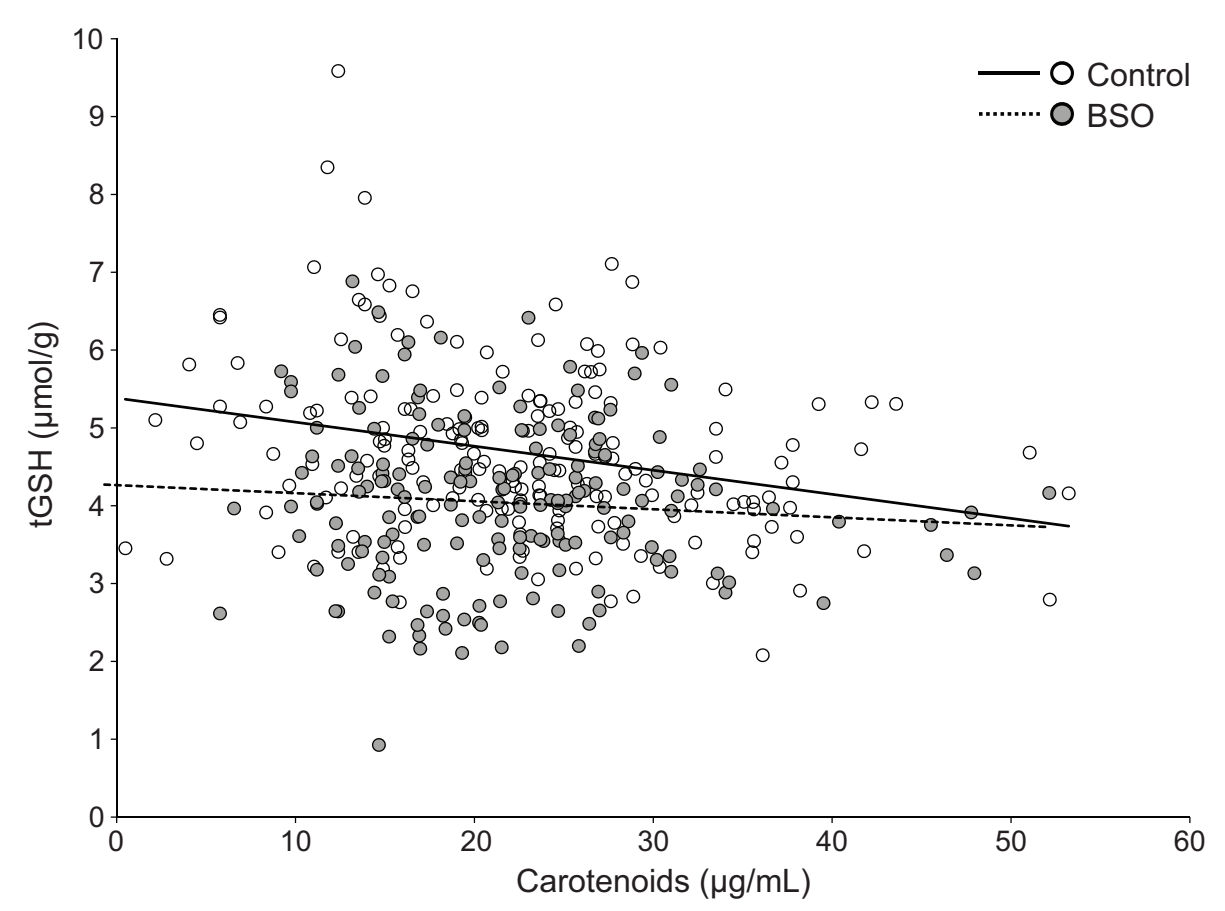

Figure 5: Relationship between total glutathione (tGSH) in erythrocytes and plasma carotenoid levels in nestlings. Dots represent raw data, the slopes being obtained from ordinary linear regressions. Slopes from mixed linear models in Results. BSO = buthionine sulfoximinetreated birds.

tits injected with similar BSO amounts showed higher, rather than lower, PLAOX values than controls. The disagreement in results could be explained by interactions with factors differing between studies, such as environmental conditions (captive vs. wild), dietary antioxidant levels, or phylogenetic distance (different species). In Horak et al. (2010), greenfinches (Carduelis chloris) exposed to similar BSO doses did not report different PLAOX values, but their sample sizes were lower ( 30 birds per treatment), with only adults being studied. A decrease in PLAOX such as that shown here could, in any case, be predicted if the tGSH depletion led to the exhaustion of PLAOX, if they were used for compensating for an antioxidant imbalance (Halliwell and Gutteridge 2007).

The fact that most significant effects arose in adulthood suggests that glutathione depletion during the first days of life did not constrain the development of an optimal phenotype but acted as a signal promoting resource reallocation. Because glutathione is synthesized from some amino acids (Isaksson et al. 2011), low glutathione levels during growth could indicate low protein availability in the environment, producing thrifty phenotypes in adulthood (sensu Hales and Barker 1992; Wells 2007). This could explain the larger size-corrected body masses of BSO females but not the lack of a similar effect in males. However, female birds increase in body mass by $7 \%-30 \%$ before reproduction (review in Lind et al. 2010), and wild zebra finch females show a greater amplitude in annual body mass change than males (Rozman et al. 2003). Moreover, egg-laying capacity in female zebra finches mostly relies on protein stores in pectoral muscles, which lose muscle mass during reproduction (Houston et al. 1995b). Interestingly, egg production in this species depends on

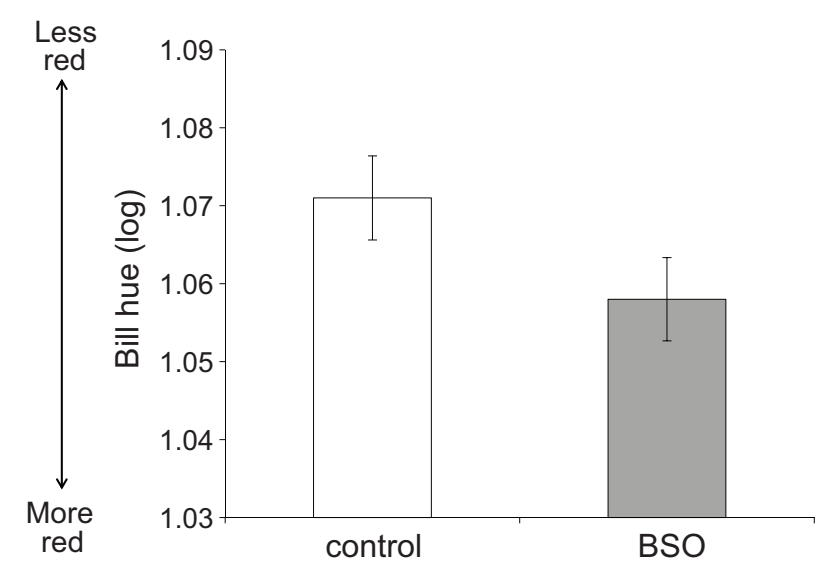

Figure 6: Bill hue of adult zebra finches in both sexes. Low hue values represent redder bills. Least squared means \pm SE from mixed models. $\mathrm{BSO}=$ buthionine sulfoximine-treated birds. 
methionine reserves in the muscle (Houston et al. 1995a), with methionine being one of the sulfur-containing amino acids involved in glutathione synthesis (Isaksson et al. 2011). Alternatively, higher body masses in BSO females may have been due to fatness. In fact, the thrifty phenotype hypothesis has mostly been linked to changes in glucose (insulin resistance) and lipid metabolism that lead to obese adults when nutritional conditions improve (McMillen and Robinson 2005; Wells 2007). However, differences in circulating TRG levels, which are an index of fatness in passerines (e.g., Jenni-Eiermann and Jenni 1994; Mandin and Vézina 2012), were not detected $(P>.26$ at both ages). Moreover, body mass gain from 21 to 40 days of age positively correlated with muscle scores but not fat scores, also in zebra finches (Alonso-Alvarez et al. 2007).

In males, as mentioned above, the treatment effect on body mass was less evident. BSO males showed a body mass (also size-corrected) decrease between sexual maturity and adulthood compared with other groups (fig. $2 A, 2 C$ ), but the difference between treatments was not significant at any sampling time. If we assume that phenotypic changes in BSO birds favored fitness, we can argue that female fitness mostly relies on energy storage allowing egg production, whereas male fitness strongly depends on attracting females, the latter depleting body reserves before reproductive age. However, no sex-related difference in the sex-dichromatic bill was found (i.e., the impact of BSO on bill color was similar in both males and females; see below). Nonetheless, a higher investment of males in other sex-dimorphic traits, such as the song, could have explained the different effect of BSO in the body mass of males and females. Male and female zebra finches were separated in different aviaries, but they were not acoustically isolated, with undirected male singing (Dunn and Zann 1996) being often observed. We must take into account that male song leads to body mass loss in some passerines (Thomas 2002; Thomas et al. 2003) and is energetically costly in male zebra finches (Franz and Goller 2003). We should also consider the possibility that sexual segregation could have induced some sort of social stress (e.g., Remage-Healey et al. 2003; Pérez et al. 2012), which was perhaps stronger in males. We must, however, note that adult birds were not mated and then separated, which induces physiological stress (Remage-Healey et al. 2003). Moreover, allowing direct contact between sexes would have increased individual variability in reproductive investment, complicating the analyses.

The best support for increased resource allocation to reproduction comes, in any case, from the fact that both BSO-treated male and female birds produced redder bills compared with controls. This should be the result of higher carotenoid concentration in the ornament (McGraw and Toomey 2010). Plasma carotenoid levels are commonly positively related to bill redness in birds, including zebra finches (McGraw 2006). However, that link was not detected here. This should not be considered unusual when the color also depends on the rate of carotenoid biotransformation in the bill tissue (McGraw 2006). In zebra finches, red bill coloration is mostly due to ketocarotenoids (e.g., astaxanthin; McGraw and Toomey 2010), which are enzymatically obtained from dietary yellow hydroxycarotenoids (e.g., zeaxanthin; McGraw 2006; García de Blas et al. 2014). Biotransformation of substrate carotenoids involves oxidation of hydroxycarotenoids by ketolases, which could be affected by the oxidative metabolism of each bird (Völker 1957; Johnson and Hill 2013). We may propose that higher oxidative stress in adult BSOtreated birds (see fig. $4 B, 4 C$ ) could have promoted carotenoid transformations in adults. Interestingly, an immune challenge was able to stimulate carotenoid-based coloration in a seabird (Sula nebouxii; Velando et al. 2014), the immune challenge being in turn associated with higher oxidative stress (Hasselquist and Nilsson 2012). How such a stimulatory effect can influence the reliability of the colored traits as signals of individual quality (e.g., Simons et al. 2012) is nevertheless unclear (Velando et al. 2014). In any case, we may suggest that birds producing redder bills should strongly invest in current reproduction, because they could pay delayed costs, such as accelerated senescence due to higher oxidative stress (see free radical theory of aging; e.g., Kirkwood and Austad 2000; but see also Sohal and Orr 2012). We must also consider that the zebra finch is a relatively short-lived species (Zann 1996), with early breeding being key to lifetime fitness (Alonso-Alvarez et al. 2006; Adkins-Regan and Tomaszicky 2007).

One interesting finding is that a negative correlation between RBC tGSH and plasma carotenoid levels arose in control nestlings but not in BSO nestlings or among adults (fig. 5). We have previously described the same negative link in an independent sample of nestling, but not adult, zebra finches (Romero-Haro and Alonso-Alvarez 2014a), which suggests some compensatory mechanism activated in those nestlings circulating few carotenoids. Here, BSO birds would have been unable to compensate (fig. 5), perhaps contributing to higher oxidative stress in adulthood.

We have provided some proximate explanations to the most evident phenotypic changes (i.e., thrifty phenotype for female body mass variability and oxidative stress-promoted pigment biotransformation for color differences), also predicting higher fitness returns (the ultimate explanation). However, considering the role of glutathione in cell signaling (Jones 2006; Ghezzi and Di Simplicio 2009) and the fact that this antioxidant is present in every tissue (Wu et al. 2004), a general regulatory mechanism can also be proposed. At first glance, the results suggest a compensatory (hormetic) response against a mild stressor, 
which may improve fitness (Costantini et al. 2010). This process could involve some signaling pathway.

An important theoretical attempt is currently being made to understand how the organism integrates information from different physiological systems to solve evolutionary life-history trade-offs. Different concepts have been coined such as control system (Lessells 2008), integrator networks (Martin et al. 2011), physiological regulatory networks (Cohen et al. 2012), or homeostatic systems (Woods and Wilson 2013). These concepts have mostly been based on the role of hormones (steroids) and cytokines (proteins involved in immune function) as chemical signals. Nevertheless, these attempts have virtually ignored redox signaling. Evolutionary ecologists are currently addressing the role of oxidative stress in lifehistory theory (Dowling and Simmons 2009; Monaghan et al. 2009; Metcalfe and Alonso-Alvarez 2010; Speakman and Garratt 2013; Costantini 2014). However, the idea of redox-active molecules acting as organizers of phenotypic plasticity, although briefly mentioned in Metcalfe and Alonso-Alvarez (2010) or Speakman and Garratt (2013), is ignored in favor of the view of oxidative stress as a constraint (Dowling and Simmons 2009; Monaghan et al. 2009; Costantini 2014). Only Isaksson et al. (2011) have highlighted the biomedical background, suggesting that glutathione may act as a signal involved in life-history trade-offs. Our results support their hypothesis.

We cannot discard the possibility that the impact of glutathione depletion on adult phenotypes was independent of signaling mechanisms, that is, that it was merely due to oxidant accumulation when antioxidant enzymes (e.g., glutathione peroxidase) do not have enough glutathione to be used to detoxify cells (see also low PLAOX values during growth). However, oxidative stress is the principal force in regulating redox signaling (Ghezzi and Di Simplicio 2009; Sohal and Orr 2012). Moreover, the glutathione role in cell signaling could be independent from oxidative stress. First, glutathione may enter into the cell nucleus altering chromatin and histones, probably exerting a deep influence on epigenetic inheritance (Markovic et al. 2010). Second, cell signaling can be mediated by gluthationylation (i.e., the conjugation of glutathione with thiol residues of different proteins; Cotgreave and Gerdes 1998). Gluthationylation can be triggered by oxidative stress when the GSH : GSSG ratio is reduced (no $\rightarrow$ seen here), but it can also be generated by specific enzymes potentially acting independently of oxidative stress (Ghezzi 2013). Glutathionylation has attracted the attention of biomedicine because it is a potent mechanism for posttranslational modification of metabolic and regulatory proteins, influencing pathways from energy metabolism tc $\rightarrow$ inflammation and apoptosis (Dalle-Donne et al. 2009; Zhang and Forman 2012; Ghezzi 2013). However, its func- tion in the physiological systems of the organism of animals as a whole is still poorly understood, with most information being inferred from in vitro studies on cell lines or tissues (Ghezzi 2013). Interestingly, reduced glutathionylation has been reported in mammalian cells exposed to BSO (e.g., Kim et al. 2010; Lin et al. 2012). We can only speculate about how glutathionylation may have mediated our results. For instance, reduced glutathionylation may have favored the activity of glycolytic enzymes, leading to cell proliferation (Dalle-Donne et al. 2009).

To conclude, although most proximate mechanisms involved in the regulation of phenotypic traits by glutathione cannot be ascertained, results support an organizer role for this ubiquitous antioxidant. Ultimately, in terms of fitness, the costs and benefits of the proposed control or regulatory system (Lessells 2008) will be fully understood only after analyzing the entire life span of individuals. In this regard, the impact that our manipulation exerts on individual reproductive success and life-history trajectories is currently the subject of a long-term study on the same zebra finches. To test the hypothesized system and fitness consequences under natural free-living conditions is a challenge for the future.

\section{Acknowledgments}

We are grateful to M. E. Ferrero, E. García de Blas, R. Mateo, and L. Ramírez Rodríguez for helping during laboratory analyses and blood sampling. We thank H. J. Forman and P. Ghezzi for fruitful discussions on the role of glutathionylation in cell signaling. We thank J. L. Bronstein and E. Adkins-Regan and two anonymous referees for their valuable comments on early drafts of the manuscript. A.A.R.H. was funded by a Formación de Personal de Investigación grant (BES-2010-035013; Ministerio de Economía y Competitividad [MINECO], Spain). Financial support was obtained from the projects CGL-2009-10883C02-02 and CGL2012-40229-C02-01 (MINECO).

\section{Literature Cited}

Adkins-Regan, E., and M. Tomaszycki. 2007. Monogamy on the fast track. Biology Letters 3:617-619.

Agarwal, R., and S. D. Chase. 2002. Rapid, fluorimetric-liquid chromatographic determination of malondialdehyde in biological samples. Journal of Chromatography B 775:121-126.

Alonso-Alvarez, C., S. Bertrand, G. Devevey, J. Prost, B. Faivre, O. Chastel, and G. Sorci. 2006. An experimental manipulation of lifehistory trajectories and resistance to oxidative stress. Evolution 60: 1913-1924.

Alonso-Alvarez, C., S. Bertrand, B. Faivre, and G. Sorci. 2007. Increased susceptibility to oxidative damage as a cost of accelerated somatic growth in zebra finches. Functional Ecology 21:873-879. 
$\rightarrow$ Alonso-Alvarez, C., and I. Galván. 2011. Free radical exposure create $\rightarrow$ paler carotenoid-based ornaments: a possible interaction in the expression of black and red traits. PLoS ONE 6:e19403.

$\rightarrow$ Alonso-Alvarez, C., L. Pérez-Rodríguez, R. Mateo, O. Chastel, and J. Viñuela. 2008. The oxidation handicap hypothesis and the carotenoid allocation trade-off. Journal of Evolutionary Biology $21 \rightarrow$ 1789-1797.

Alonso-Alvarez, C., and A. Velando. 2012. Benefits and costs of parental care. Pages 40-61 in N. J. Royle, P. T. Smiseth, and M Kolliker, eds. The evolution of parental care. Oxford University Press, Oxford.

$\rightarrow$ Barnes, A. I., and L. Partridge. 2003. Costing reproduction. Anima $\rightarrow$ Behaviour 66:199-204.

Braendle, C., A. Heyland, and T. Flatt. 2011. Integrating mechanistic and evolutionary analysis of life history variation. Pages 3-10 in T. Flatt and A. Heyland, eds. Mechanisms of life history evolution. Oxford University Press, Oxford.

$\rightarrow$ Burley, N. 1986. Sexual selection for aesthetic traits in species with biparental care. American Naturalist 127:415-445.

$\rightarrow$ Chen, J. H., M. S. Martin-Gronert, J. Tarry-Adkins, and S. E. Ozanne. 2009. Maternal protein restriction affects postnatal growth and the expression of key proteins involved in lifespan regulation in mice. PLoS ONE 4:e4950.

$\rightarrow$ Chung, T. K., M. A. Funk, and D. H. Baker. 1990. L-2-oxothiazolidine-4-carboxylate as a cysteine precursor: efficacy for growth and hepatic glutathione synthesis in chicks and rats. Journal o Nutrition 120:158-165.

$\rightarrow$ Cohen, A., K. Klasing, and R. Ricklefs. 2007. Measuring circulating antioxidants in wild birds. Comparative Biochemistry and Phys iology B 147:110-121.

$\rightarrow$ Cohen, A., L. B. Martin, J. C. Wingfield, S. R. McWilliams, and J. A. Dunne. 2012. Physiological regulatory networks: ecological role and evolutionary constraints. Trends in Ecology and Evolution 27: 428-435.

$\rightarrow$ Cohen, J. 1992. A power primer. Psychological Bulletin 112:155-159 $\rightarrow$

$\rightarrow$ Costantini, D. 2011. On the measurement of circulating antioxidant capacity and the nightmare of uric acid. Methods in Ecology and Evolution 2:321-325.

. 2014. Oxidative stress and hormesis in evolutionary ecology and physiology. Springer, Berlin.

$\rightarrow$ Costantini, D., N. B. Metcalfe, and P. Monaghan. 2010. Ecological processes in a hormetic framework. Ecology Letters 13:1435-1447.

$\rightarrow$ Cotgreave, I. A., and R. G. Gerdes. 1998. Recent trends in glutathione biochemistry-glutathione-protein interactions: a molecular linl between oxidative stress and cell proliferation? Biochemical and Biophysical Research Communications 242:1-9.

$\rightarrow$ Dalle-Donne, I., R. Rossi, G. Colombo, D. Giustarini, and A. Milzani. 2009. Protein S-glutathionylation: a regulatory device from bacteria to humans. Trends in Biochemical Sciences 34:85-96.

$\rightarrow$ De Jong, G., and A. J. Van Noordwijk. 1992. Acquisition and allocation of resources: genetic (co)variances, selections and life histories. American Naturalist 139:749-770.

$\rightarrow$ De Quiroga, G. B., M. Lopez-Torres, R. Perez-Campo, M. Abelenda, M. P. Nava, and M. L. Puerta. 1991. Effect of cold-acclimation on GSH, antioxidant enzymes and lipid-peroxidation in browr $\rightarrow$ adipose-tissue. Biochemical Journal 277:289-292.

$\rightarrow$ Del Vesco, A. P., E. Gasparino, D. O. Grieser, V. Zancanela, F. R. Gasparin, J. Constantin, and A. R. Oliveira Neto. 2014. Effects o $\rightarrow$ methionine supplementation on the redox state of acute heat stress-exposed quails. Journal of Animal Science 92:806-815.
Dennery, P. A. 2010. Oxidative stress in development: nature or nurture? Free Radical Biology and Medicine 49:1147-1151.

$\rightarrow$ Dowling, D. K., and L. W. Simmons. 2009. Reactive oxygen species as universal constraints in life-history evolution. Proceedings of the Royal Society B: Biological Sciences 276:1737-1745.

Dunn, A. M., and R. A. Zann. 1996. Undirected song in wild zebra finch flocks: contexts and effects of mate removal. Ethology 102: 529-539.

Enkvetchakul, B., and W. G. Bottje. 1995. Influence of diethyl maleate and cysteine on tissue glutathione and growth in broiler-chickens. Poultry Science 74:864-873.

Feoli, A. M., I. Siqueira, L. M. V. Almeida, A. C. Tramontina, C. Battu, S. T. Wofchuk, C. Gottfried, M. L. Perry, and C. A. Gonçalves. 2006. Brain glutathione content and glutamate uptake are reduced in rats exposed to pre- and postnatal protein malnutrition. Journal of Nutrition 136:2357-2361.

$\rightarrow$ Fetoui, H., A. Mahjoubi-Samet, K. Jamoussi, F. Ayadi, F. Ellouze, and N. Zeghal. 2007. Food restriction in pregnant and lactating rats induces anemia and increases plasma lipid peroxidation in their progeny. Nutrition Research 27:788-793.

Foley, J. D., and A. Van Dam. 1984. Fundamentals of interactive computer graphics. Addison-Wesley, Reading, MA.

Franz, M., and M. Goller. 2003. Respiratory patterns and oxygen consumption in singing zebra finches. Journal of Experimental Biology 206:967-978.

$\rightarrow$ Galván, I., and C. Alonso-Alvarez. 2008. An intracellular antioxidant determines the expression of a melanin-based signal in a bird. PLoS ONE 3:e3335.

- 2009. The expression of melanin-based plumage is separately modulated by exogenous oxidative stress and a melanocortin. Proceedings of the Royal Society B: Biological Sciences 276:3089-3097.

Galvani, P., P. Fumagalli, and A. Santagostino. 1998. Glutathione depletion by xenobiotics in Coturnix coturnix japonica. Bulletin of Environmental Contamination and Toxicology 60:909-915.

García-de Blas, E., R. Mateo, F. J. Guzmán Bernardo, R. C. Rodríguez Martín-Doimeadios, and C. Alonso-Alvarez. 2014. Astaxanthin and papilioerythrinone in the skin of birds: a chromatic convergence of two metabolic routes with different precursors? Naturwissenschaften 101:407-416.

Gerisch, B., and A. Antebi. 2011. Molecular basis of life history regulation in C. elegans and other organisms. Pages 284-298 in T. Flatt and A. Heyland, eds. Mechanisms of life history evolution. Oxford University Press, Oxford.

Ghezzi, P. 2013. Protein glutathionylation in health and disease. Biochimica et Biophysica Acta 1830:3165-3172.

Ghezzi, P., and P. Di Simplicio. 2009. Protein glutathiolation. Pages 123-142 in C. Jacob and P. G. Winyard, eds. Redox signaling and regulation in biology and medicine. Wiley, Weinheim.

Gibbs, P. 2008. An introduction to generalized linear mixed models using SAS PROC GLIMMIX. SAS Technical Support, University of California at Riverside, Riverside, CA.

Godwin, J., J. A. Luckenbach, and R. J. Borski. 2003. Ecology meets endocrinology: environmental sex determination in fishes. Evolution and Development 5:40-49.

Gore, A. C. 2008. Developmental programming and endocrine disruptor effects on reproductive neuroendocrine systems. Frontiers in Neuroendocrinology 29:358-374.

Griffith, O. W. 1980. Determination of glutathione and glutathione disulfide using glutathione reductase and 2-vinilpiridine. Analytical Biochemistry 106:207-212. 
$\rightarrow-$ 1982. Mechanism of action, metabolism, and toxicity o buthionine sulfoximine and its higher homologs, potent inhibitors of glutathione synthesis. Journal of Biological Chemistry 257: 13704-13712.

$\rightarrow$ Hales, C. N., and D. J. Barker. 1992. Type 2 (non-insulin-dependent, diabetes mellitus: the thrifty phenotype hypothesis. Diabetologia 35:595-601.

Halliwell, B., and J. M. C. Gutteridge. 2007. Free radicals in biology and medicine. 4th ed. Oxford University Press, Oxford.

$\rightarrow$ Hasselquist, D., and J. A. Nilsson. 2012. Physiological mechanisms mediating costs of immune responses: what can we learn from studies of birds? Animal Behaviour 83:1303-1312.

$\rightarrow$ Hernández-García, D., C. D. Wood, S. Castro-Obregón, and L. Covarrubias. 2010. Reactive oxygen species: a radical role in development? Free Radical Biology and Medicine 49:130-143.

$\rightarrow$ Hõrak, P., E. Sild, U. Soomets, T. Sepp, and K. Kilk. 2010. Oxidative stress and information content of black and yellow plumage coloration: an experiment with greenfinches. Journal of Experimental Biology 213:2225-2233.

$\rightarrow$ Houston, D. C., D. Donnan, and P. J. Jones. 1995a. Use of labellec $\rightarrow$ methionine to investigate the contribution of muscle protein to egg production in zebra finches. Journal of Comparative Physiology B 165:161-164.

$\rightarrow$ Houston, D. C., D. Donnan, P. J. Jones, I. Hamilton, and D. Osborne $\rightarrow$ $1995 b$. Changes in the muscle condition of female zebra finches Poephila guttata during egg-laying and the role of protein storag, in bird skeletal-muscle. Ibis 137:322-332.

$\rightarrow$ Isaksson, C. 2013. Opposing effects on glutathione and reactive oxygen metabolites of sex habitat, and spring date, but no effect of increased breeding density in great tits (Parus major). Ecology anc Evolution 3:2730-2738.

$\rightarrow$ Isaksson, C., B. C. Sheldon, and T. Uller. 2011. The challenges of integrating oxidative stress into life-history biology. Bioscience 61: 194-202.

$\rightarrow$ Jahoor, F., L. J. Wykes, P. J. Reeds, J. F. Henry, M. P. del Rosario, and M. E. Frazer. 1995. Protein-deficient pigs cannot maintain reduced glutathione homeostasis when subjected to the stress o inflammation. Journal of Nutrition 125:1462-1472.

$\rightarrow$ Jenni-Eiermann, S., and L. Jenni. 1994. Plasma metabolite levels predict individual body mass changes in a small long-distanc migrant, the garden warbler. Auk 111:888-899.

$\rightarrow$ Johnson, J. D., and G. E. Hill. 2013. Is carotenoid ornamentation linked to the inner mitochondria membrane potential? a hypothesis for the maintenance of signal honesty. Biochimie 95:436-444 $\rightarrow$

$\rightarrow$ Jones, D. 2006. Redefining oxidative stress. Antioxidants and Redox Signaling 8:1865-1879.

$\rightarrow$ Kiani, A., and M. O. Nielsen. 2011. Metabolic programming: origin of non-communicable diseases in early life nutrition. International Journal of Endocrinology and Metabolism 9:409-415.

$\rightarrow$ Kim, Y., Y. B. Song, T. Y. Kim, I. Kim, S. J. Han, Y. Ahn, S. H. Cho, et al. 2010. Redox regulation of the tumor suppressor PTEN by glutathione. FEBS Letters 584:3550-3556.

$\rightarrow$ Kirkwood, T. B. L., and S. N. Austad. 2000. Why do we age? Nature 408:233-238.

$\rightarrow$ Leggatt, R. A., C. J. Brauner, P. M. Schulte, and G. K. Iwama. 2007. Effects of acclimation and incubation temperature on the gluta $\rightarrow$ thione antioxidant system in killifish and RTH-149 cells. Comparative Biochemistry and Physiology A 146:317-326.

$\rightarrow$ Leroi, A. 2001. Molecular signals versus the Loi de Balancement. Trends in Ecology and Evolution 16:24-29.
Lessells, C. K. M. 2008. Neuroendocrine control of life histories: what do we need to know to understand the evolution of phenotypic plasticity? Philosophical Transactions of the Royal Society B: Biological Sciences 363:1589-1598.

Levin, B. E. 2006. Metabolic imprinting: critical impact of the perinatal environment on the regulation of energy homeostasis. Philosophical Transactions of the Royal Society B: Biological Sciences 361:1107-1121.

Lin, Y. C., G. D. Huang, C. W. Hsieh, and B. S. Wung. 2012. The glutathionylation of p 65 modulates NF- $\kappa$ B activity in 15 -deoxy$\delta(1)(2)$, (1)(4)-prostaglandin J(2)-treated endothelial cells. Free Radical Biology and Medicine 52:1844-1853.

Lind, J., S. Jakobsson, and C. Kullberg. 2010. Impaired predator evasion in the life history of birds: behavioral and physiological adaptations to reduced flight ability. Pages 1-30 in C. F. Thompson, ed. Current ornithology. Springer, Berlin.

Littell, R. C., G. A. Milliken, W. W. Stroup, R. D. Wolfinger, and O. Schabenberger. 2006. SAS system for mixed models. SAS Institute, Cary, NC.

López-Torres, M., and G. Barja. 2008. Lowered methionine ingestion as responsible for the decrease in rodent mitochondrial oxidative stress in protein and dietary restriction possible implications for humans. Biochimica et Biophysica Acta 1780:1337-1347.

Lu, S. C. 2013. Glutathione synthesis. Biochimica et Biophysica Acta 1830:3143-3153.

Luo, Z. C., W. D. Fraser, P. Julien, C. L. Deal, F. Audibert, G. N. Smith, X. Xiong, and M. Walker. 2006. Tracing the origins of "fetal origins" of adult diseases: programming by oxidative stress? Medical Hypotheses 66:38-44.

Mandin, C., and F. Vézina. 2012. Daily variation in markers of nutritional condition in wintering black-capped chickadees Poecile atricapillus. Ibis 1859:791-802.

Marchionatti, A., A. Alisio, G. Díaz de Barboza, V. Baudino, and N. Tolosa de Talamoni. 2001. DL-Buthionine-S,R-sulfoximine affects intestinal alkaline phosphatase activity. Comparative Biochemistry and Physiology C 129:85-91.

Markovic, J., J. L. García-Gimenez, A. Gimeno, J. Viña, and F. V. Pallardó. 2010. Role of glutathione in cell nucleus. Free Radical Research 44:721-733.

Mårtensson, J., A. Jain, E. Stole, W. Frayer, P. A. Auld, and A. Meister. 1991. Inhibition of glutathione synthesis in the newborn rat: a model for endogenously produced oxidative stress. Proceedings of the National Academy of Sciences of the USA 88:9360-9364.

Martin, L. B., A. L. Liebl, J. H. Trotter, C. L. Richards, K. McCoy, and M. W. McCoy. 2011. Integrator networks: illuminating the black box linking genotype and phenotype. Integrative and Comparative Biology 51:514-527.

McArdle, H. J., H. S. Andersen, H. Jones, and L. Gambling. 2006. Fetal programming: causes and consequences as revealed by studies of dietary manipulation in rats: a review. Placenta 27(suppl.):S56S60.

McGraw, K. J. 2006. Mechanics of carotenoid-based coloration. Pages 177-242 in G. E. Hill and K.J. McGraw, eds. Bird coloration: mechanisms and measurements. Harvard University Press, Cambridge, MA.

McGraw, K. J., and M. B. Toomey. 2010. Carotenoid accumulation in the tissues of zebra finches: predictors of integumentary pigmentation and implications for carotenoid allocation strategies. Physiological and Biochemical Zoology 83:97-109.

$\rightarrow$ McMillen, I. C., and J. S. Robinson. 2005. Developmental origins of 
the metabolic syndrome: prediction, plasticity, and programming. Physiological Reviews 85:571-633.

$\rightarrow$ Metcalfe, N. B., and C. Alonso-Alvarez. 2010. Oxidative stress as a life-history constraint: the role of reactive oxygen species in shaping phenotypes from conception to death. Functional Ecology 24: 984-996.

$\rightarrow$ Metcalfe, N. B., and P. Monaghan. 2001. Compensation for a bad start: grow now, pay later? Trends in Ecology and Evolution 16: 254-260.

$\rightarrow$ Miller, N. J., C. A. Rice-Evans, M. J. Davies, V. Gopinathan, and A $\rightarrow$ Milner. 1993. A novel method for measuring antioxidant capacity and its application to monitoring the antioxidant status in premature neonates. Clinical Science 84:407-412.

$\rightarrow$ Monaghan, P., N. B. Metcalfe, and R. Torres. 2009. Oxidative stress as a mediator of life history trade-offs: mechanisms, measurements and interpretation. Ecology Letters 12:75-92.

$\rightarrow$ Németh, K., M. Mézes, T. Gaál, A. Bartos, K. Balogh, and F. Husvéth. 2004. Effect of supplementation with methionine and different fat sources on the glutathione redox system of growing chickens. Acta Veterinaria Hungarica 52:369-378.

$\rightarrow$ Nussey, D. H., J. M. Pemberton, J. G. Pilkington, and J. D. Blount. 2009. Life history correlates of oxidative damage in a freelivin mammal population. Functional Ecology 23:809-817.

$\rightarrow$ Nuyt, M. A., and B. T. Alexander. 2009. Developmental programming and hypertension. Current Opinion in Nephrology and Hypertension 18:144-152.

Owen, J., and D. Butterfield. 2010. Measurement of oxidized/reduced glutathione ratio. Pages 269-277 in P. Bross and N. Gregersen, eds. Methods in molecular biology. Vol. 648. Protein misfoldin and cellular stress in diseases and aging: concepts and protocols. Springer, New York.

$\rightarrow$ Partadiredja, G., S. Worrall, and K. S. Bedi. 2009. Early life undernutrition alters the level of reduced glutathione but not the activity levels of reactive oxygen species enzymes or lipid peroxidation in the mouse forebrain. Brain Research 1285:22-29.

$\rightarrow$ Pérez, E. C., J. E. Elie, C. O. Soulage, H. A. Soula, N. Mathevon, and C. Vignal. 2012. The acoustic expression of stress in a songbird: does corticosterone drive isolation-induced modifications of zebra finch calls? Hormones and Behavior 61:573-581.

$\rightarrow$ Pike, T. W., and M. Petrie. 2003. Potential mechanisms of avian sey manipulation. Biological Reviews 78:553-574.

$\rightarrow$ Reid, M., A. Badaloo, T. Forrester, J. F. Morlese, M. Frazer, W. C. Heird, and J. Jahoor. 2000. In vivo rates of erythrocyte glutathione synthesis in children with severe protein-energy malnutrition. American Journal of Physiology Endocrinology and Metabolism 278:E405-E412.

$\rightarrow$ Remage-Healey, L., E. Adkins-Regan, and L. M. Romero. 2003. Behavioral and adrenocortical responses to mate separation and reunion in the zebra finch. Hormones and Behavior 43:108-114.

$\rightarrow$ Rinaudo, P., and E. Wang. 2012. Fetal programming and metabolic syndrome. Annual Review of Physiology 74:107-130.

Roff, D. A. 2011. Genomic insights into life history evolution. Page 11-25 in T. Flatt and A. Heyland, eds. Mechanisms of life history evolution. Oxford University Press, Oxford.

$\rightarrow$ Rojas, R. R., and R. A. Leopold. 1996. Chilling injury in the housefly: evidence for the role of oxidative stress between pupariation and emergence. Cryobiology 33:447-458.

$\rightarrow$ Romero-Haro, A. A., and C. Alonso-Alvarez. 2014a. Covariation in oxidative stress markers in the blood of nestling and adult birds. Physiological and Biochemical Zoology 87:353-362. 2014b. Data from: The level of an intracellular antioxidant during development determines the adult phenotype in a bird species: a potential organizer role for glutathione. American Naturalist, Dryad Digital Repository, http://dx.doi.org/10.5061 /dryad.1rd58.

Round, P. D., B. Hansson, D. J. Pearson, P. R. Kennerley, and S. Bensch. 2007. Lost and found: the enigmatic large-billed reed warbler Acrocephalus orinus rediscovered after 139 years. Journal of Avian Biology 38:133-138.

Rozman, J., D. Runciman, and R. A. Zann. 2003. Seasonal variation in body mass and fat of zebra finches in south-eastern Australia. Emu 103:11-19.

$\rightarrow$ Schielzeth, H., and W. Forstmeier. 2009. Conclusions beyond support: overconfident estimates in mixed models. Behavioral Ecology 20:416-420.

$\rightarrow$ Simons, M. J. P., M. Briga, E. Koetsier, R. Folkertsma, M. D. Wubs, C. Dijkstra, and S. Verhuslt. 2012. Bill redness is positively associated with reproduction and survival in male and female zebra finches. PLoS ONE 7:e40721.

Sohal, R. S., and W. C. Orr. 2012. The redox stress hypothesis of aging. Free Radical Biology and Medicine 52:539-555.

Speakman, J. R., and M. Garratt. 2013. Oxidative stress as a cost of reproduction: beyond the simplistic trade-off model. Bioessays 36 : 93-106.

Stearns, S. C. 2011. Does impressive progress on understanding mechanisms advance life history theory? Pages 365-674 in T. Flatt and A. Heyland, eds. Mechanisms of life history evolution. Oxford University Press, Oxford.

Swennen, Q., P.-A. Geraert, Y. Mercier, N. Everaert, A. Stinckens, H. Willemsen, Y. Li, P. Decuypere, and J. Buyse. 2011. Effects of dietary protein content and 2-hydroxy-4-methylthiobutanoic acid or DLmethionine supplementation on performance and oxidative status of broiler chickens. British Journal of Nutrition 106:1845-1854.

Tarry-Adkins, J. L., J. A. Joles, J. H. Chen, M. S. Martin-Gronert, D. M. van der Giezen, R. Goldschmeding, C. N. Hales, and S. E. Ozanne. 2007. Protein restriction in lactation confers nephroprotective effects in the male rat and is associated with increased antioxidant expression. American Journal of Physiology 293: R1259-R1266.

Tarry-Adkins, J. L., J. H. Chen, N. S. Smith, R. H. Jones, H. Cherif, and S. E. Ozanne. 2009. Poor maternal nutrition followed by accelerated postnatal growth leads to telomere shortening and increased markers of cell senescence in rat islets. FASEB Journal 23:1521-1528.

Thomas, R. J. 2002. The costs of singing in nightingales. Animal Behaviour 63:959-966.

Thomas, R. J., I. C. Cuthill, A. R. Goldsmith, D. F. Cosgrove, H. C. Lidgate, and S. L. B. Proctor. 2003. The trade-off between singing and mass gain in a daytime-singing bird, the European robin. Behaviour 140:387-404.

Thompson, L. P., and Y. Al-Hasan. 2012. Impact of oxidative stress in fetal programming. Journal of Pregnancy 2012:582748.

$\rightarrow$ Velando, A., R. Beamonte-Barrientos, and R. Torres. 2014. Enhanced male coloration after immune challenge increases reproductive potential. Journal of Evolutionary Biology 27:1582-1589.

$\rightarrow$ Völker, O. 1957. Die experimentelle rotfärbung des Gefieders beim Fichtenkreuzschnabel (Loxia curvirostra). Journal of Ornithology 98:210-214.

$\rightarrow$ Warner, M. J., and S. E. Ozanne. 2010. Mechanisms involved in the 
developmental programming of adulthood disease. Biochemical Journal 427:333-347.

$\rightarrow$ Wells, J. C. K. 2007. The thrifty phenotype as an adaptive maternal effect. Biological Reviews 82:143-172.

West-Eberhard, M. J. 2003. Developmental plasticity and evolution. Oxford University Press, New York.

$\rightarrow$ Włostowski, T., K. Dmowski, and E. Bonda-Ostaszewska. 2010. Cadmium accumulation, metallothionein and glutathione levels, anc $\rightarrow$ histopathological changes in the kidneys and liver of magpie (Pica pica) from a zinc smelter area. Ecotoxicology 19:1066-1073.

$\rightarrow$ Woods, H. A., and J. K. Wilson. 2013. An information hypothesis for the evolution of homeostasis. Trends in Ecology and Evolution 28:283-289.

$\rightarrow$ Wu, G., Y. Fang, S. Yang, J. R. Lupton, and N. D. Turner. 2004.
Glutathione metabolism and its implications for health. Journal of Nutrition 134:489-492.

Zann, R. A. 1996. Zebra finch: a synthesis of field and laboratory studies. Oxford University Press, Oxford.

Zera, A. J., and L. G. Harshman. 2001. The physiology of life history trade-offs in animals. Annual Review of Ecology and Systematics 32:95-126.

Zhang, H., and H. J. Forman. 2012. Glutathione synthesis and its role in redox signaling. Seminars in Cell and Developmental Biology 23:722-728.

Associate Editor: Elizabeth Adkins-Regan Editor: Judith L Bronstein

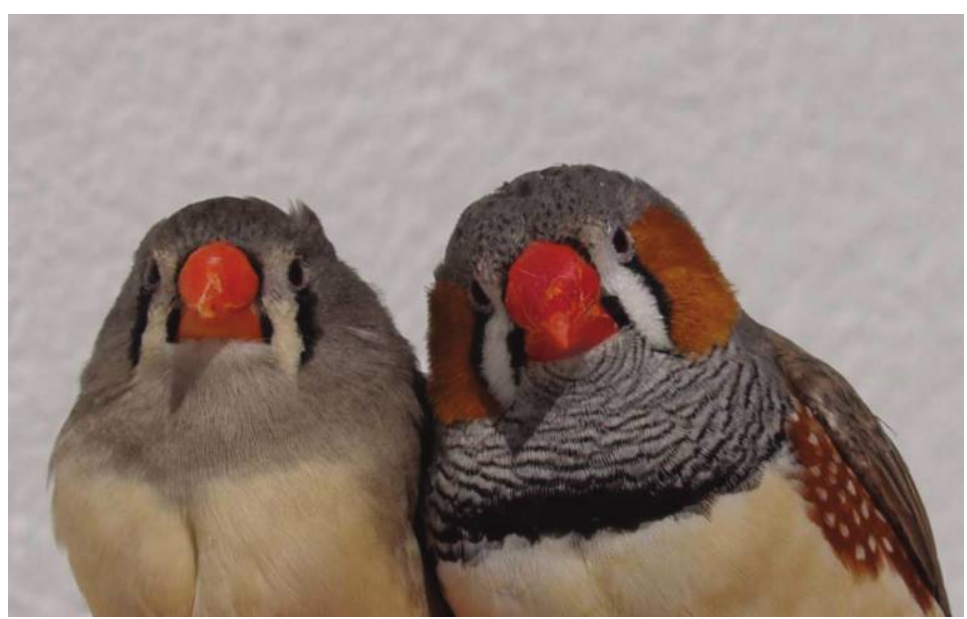

A zebra finch couple (Taeniopygia guttata); note the red bills. Photo credit: Carlos Alonso-Alvarez. 